\title{
Comparative Study of Dermatological Diseases of the Elderly in Relation to the Rest Population
}

This article was published in the following Dove Press journal:

Clinical, Cosmetic and Investigational Dermatology

lordanis Papadopoulos (D)

Department of Aesthetics and Cosmetology, Alexander Technological Educational Institute of Thessaloniki, Thessaloniki, Greece

\section{Video abstract}

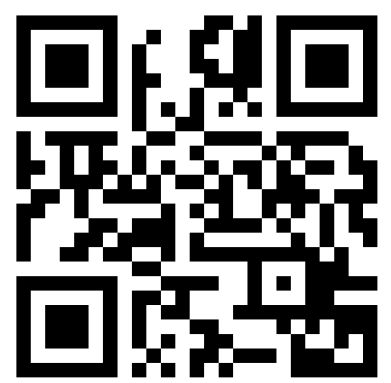

Point your SmartPhone at the code above. If you have a QR code reader the video abstract will appear. Or use: https://youtu.be/927wPiRCa70
Correspondence: lordanis Papadopoulos Email driordanis@yahoo.gr
Background: According to Eurostat, the geriatric population in Greece constitutes almost $21.8 \%$ of the total population, with an increasing tendency. Skin diseases of the elderly often originate from internal medicine diseases. The aim of this study was to identify different dermatological conditions among patients over 65 years of age compared to younger patients. Methods: The present study was conducted between May 2015 and December 2017 in public medical offices in the Municipality of Thessaloniki. A total of 8422 patients of all ages were screened and their dermatological problem was recorded. The sample was then divided into two age groups. The first group was composed of 3629 elderly patients over 65 years of age. The second group consisted of 4793 patients up to 65 years old.

Results: Pruritus was the main dermatological complaint in the elderly (14.2\%) compared to the younger age group (1\%), who were more interested in their mole examination $(15.1 \%)$. Precancerous lesions (4\%) and skin cancers $(2.4 \%)$ presented more frequently in elderly patients than in people younger than 65 years old $(0.7 \%$ and $0.5 \%$, respectively).

Conclusion: There are significant differences in the frequency and etiology of dermatological diseases between the two age groups. Pruritus and non-cancerous tumors of the elderly are considered to be the main findings of geriatric dermatology.

Keywords: geriatric dermatology, skin cancer, epidemiology, pruritus, skin ageing

\section{Introduction}

The number of elderly people tends to increase compared to the other age groups, while they constitute a significant percentage of the general population. The diseases of the elderly are usually due to aging and the gradual decline in physical activity and organ function. ${ }^{1}$ Dermatology is required to detect skin diseases in this group of patients as these are mostly the result of the internal organ pathology.

This age group of patients has some peculiarities compared to other patients. One of them is the phenomenon of polypharmacy. ${ }^{2}$ Taking combination therapies for various illnesses can increase the incidence of skin side effects, perhaps due to age-related decreased kidney and liver function. Most of the half-elderly people over 85 are frail with difficulties in their daily routine and dependent on a caregiver for daily activities, such as dressing, personal hygiene or outdoor activities such as traveling.

A large number of older people are unable to access primary care due to their mobility problems, while the cost of a medical home examination is often high and thus prohibited to them. There are also some cases of elderly with no relatives, so the difficulty in accessing medical care is even greater. The usual hearing, vision and memory disturbances due to dementia often hinder the diagnostic ability and even the therapeutic effect of doctors. 
The result of aging originates from both an endogenous and an exogenous process. The endogenous process is due to aging as a result of inheritance, cell metabolism and hormonal changes observed in the body. The manifestations of this process are gradually becoming visible from the age of thirty years and peak at the age of sixty. Age-related skin deterioration involves thinning of the epidermis, decreasing the number of the cell population of the dermis with associated reduction in its vessels and collagen as well as elastin. This change causes the decrease of skin's elasticity and leads to skin relaxation. Cellular skin changes that lead to the appearance of skin aging are as follows (Table 1).

\section{Materials and Methods}

This study was carried out as a part of primary care municipal programs in Thessaloniki, Greece from May 2015 to December 2017. A total of 8422 patients of all ages were examined. Patients' age ranged from 0 year to 99 years. Their personal data and dermatological problem were recorded. The sample was divided into two age groups. The first group included elderly patients over 65 years old and numbered 3629 patients. The second group was up to 65 years of age and had 4793 patients. $^{3}$

It was the first time that a dermatologist worked in such social structures of the topical municipalities. The examination was for free. A lot of the examined patients had financial problems. Some patients were examined in their houses because they had serious

Table I Old-Age Pathophysiology of the Skin

\begin{tabular}{|l|l|}
\hline Anatomical Changes & Clinical Picture \\
\hline $\begin{array}{l}\text { Reducing keratinocyte } \\
\text { proliferation }\end{array}$ & Epidermis thinning \\
\hline Melanocyte reduction & $\begin{array}{l}\text { Decrease tanning capacity and } \\
\text { bleaching the hair }\end{array}$ \\
\hline $\begin{array}{l}\text { Reduction of fibroblasts- } \\
\text { collagen atrophy }\end{array}$ & $\begin{array}{l}\text { Vascular Reduction Atrophy- } \\
\text { slowing of healing }\end{array}$ \\
\hline Reduction of nerve endings & Reduction of sensation \\
\hline Reduction of sebaceous \\
glands & Reduction of sweat glands \\
\cline { 2 - 3 } & Risk of heat stroke \\
\hline Hair loss & Alopecia \\
\hline Reduction of the fat & $\begin{array}{l}\text { Low tolerance to cold- thinning of } \\
\text { the face }\end{array}$ \\
\hline Delayed growth of nails & Nail diseases \\
\hline
\end{tabular}

health conditions and they could not move. They have been done 108 home visits.

The work was conducted in accordance with the COPE of Ethics of the World Medical Association (Declaration of Helsinki) for studies involving humans. Written informed consent was obtained from all patients or a parent or legal guardian for participants under the age of 18 years prior to enrollment in the study. The study was approved by the Department of the Medical Services of the Municipality of Thessaloniki. Data were analyzed by Statistical package of Social Science version (SPSS). The considered statistical significance was $\mathrm{p}<0.05$.

\section{Results}

Skin diseases, listed below, relate to the findings after the clinical dermatological examination and the histopathological report (where required) of this particular sample of 8422 patients. The five most common dermatological conditions that were of most interest to the elderly and led them to a dermatological examination were pruritus (14.2\%), various forms of eczema (12.4\%), seborrheic keratoses (6.8\%), hair loss $(6.2 \%)$ and onychomycosis with $4.9 \%$. (Figure 1).

The classification of skin diseases in the elderly by sex shows some variation (Figures 2 and 3 ).

Almost $5 \%$ of elderly men had solar keratoses while this proportion was less than $1 \%$ in elderly women.

In the overall sample, one case of melanoma was found (with multiple metastases), 3 cases of squamous cell carcinoma and 91 cases of basal cell carcinoma. Five of the male patients with basal cell carcinoma manifested more than one lesion. Primarily the oncologic incidents concerned the head and neck area and rarely other locations. All of the precancerous lesions and malignant tumors were previously undiagnosed. All suspected malignant tumors were surgically removed and sent for histological study.

There were rare cases of pompholyx red lichen, scleroderma, pemphigus, pompholyx pemphigoid, and one patient

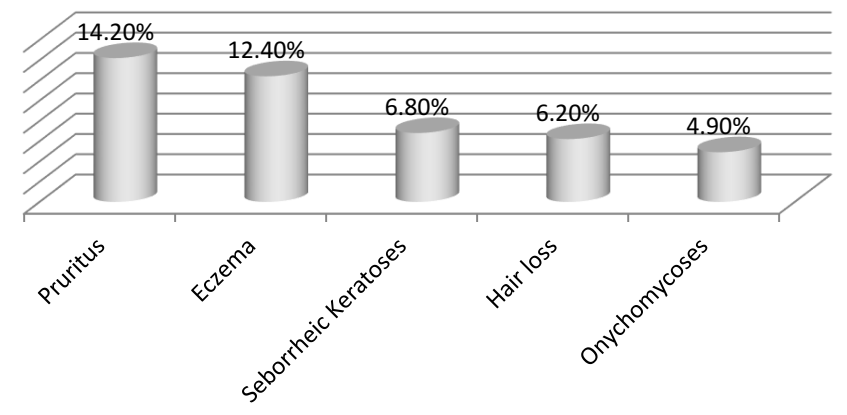

Figure I The five most common skin diseases in the elderly. 


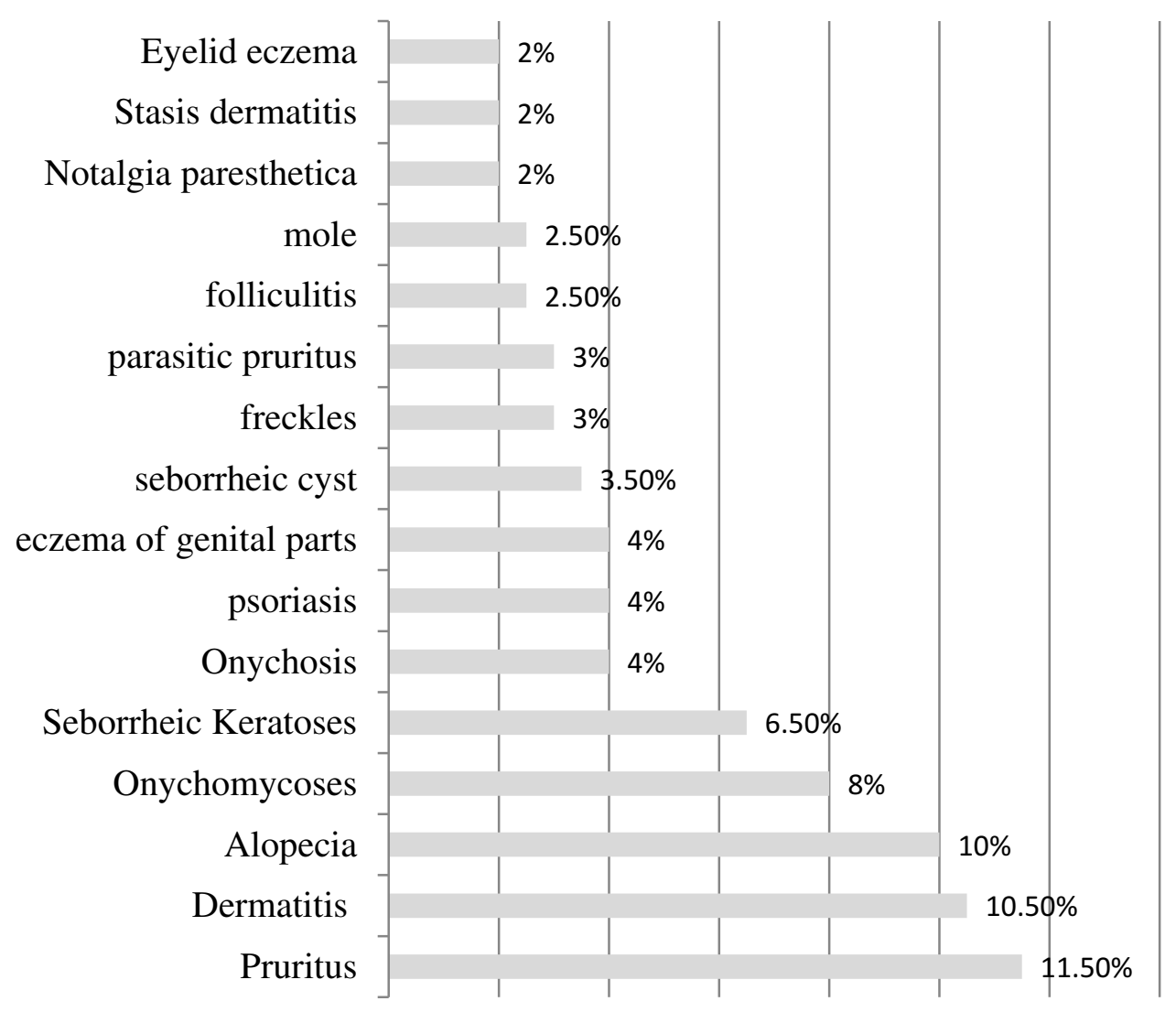

Figure 2 The most common skin diseases in elderly women.

with genital warts. A total of 108 home visits were made, which is about $3 \%$ of all patients examined. Most of these patients were bedridden due to severe neurological disorders (e.g., stroke), and some patients had a large decrease in their mobility. Other skin diseases with a particular clinical appearance were identified, such as herpes zoster, where in some cases postherpetic neuralgia exceeded one year.

The five most common dermatological conditions mostly affected patients under the age of 65 who visit a dermatological clinic were mole check (15.1\%), microbial infections $(12.9 \%)$, dermatitis $(11.4 \%)$, viral infections $(9.4 \%)$ and eczema (9.1\%). (Figure 4$)$. The cases of dermatitis were mainly related to atopic dermatitis, contact dermatitis and photodermatitis. Microbial infections were mainly related to folliculitis, doctrine and impetigo. Viral infections were mainly herpetic and those of hand-mouthfoot disease (Tables 2-3).

\section{Conclusions-Discussion}

Geriatric dermatology presents a remarkable difference in the frequency of some diseases and their treatment compared to other age groups. ${ }^{4}$
It is worth mentioning that there are many dermatological patients who ask advice from other medical specialties (e.g. for STDs) or use their own treatments (e.g. for hair loss). ${ }^{5}$ Some patients do not ask for medical advice if their dermatological problem does not bother them, or if it is not dangerous to their overall health (e.g. acne). ${ }^{6}$ Some patients have difficulty communicating for history taking because of brain disease (e.g. stroke, dementia). Unfortunately, they sometimes ask for a delayed dermatological advice when the condition is quite complex and require special and personalized therapeutic treatment due to the atrophy of aging skin as well as the probable drug interactions.

As already mentioned; eczema and dermatitis have different causes in the two age groups and have a high incidence. ${ }^{7}$ Hair loss is of greater interest to elderly patients. Onychomycosis presents with the same percentage in both samples. ${ }^{8}$

Pruritus in the elderly is the main cause leading them to the Dermatologist. ${ }^{9}$ The causes of pruritus are mostly related to skin atrophy and the presence of other diseases that manifest with pruritus as a clinical feature. In other 


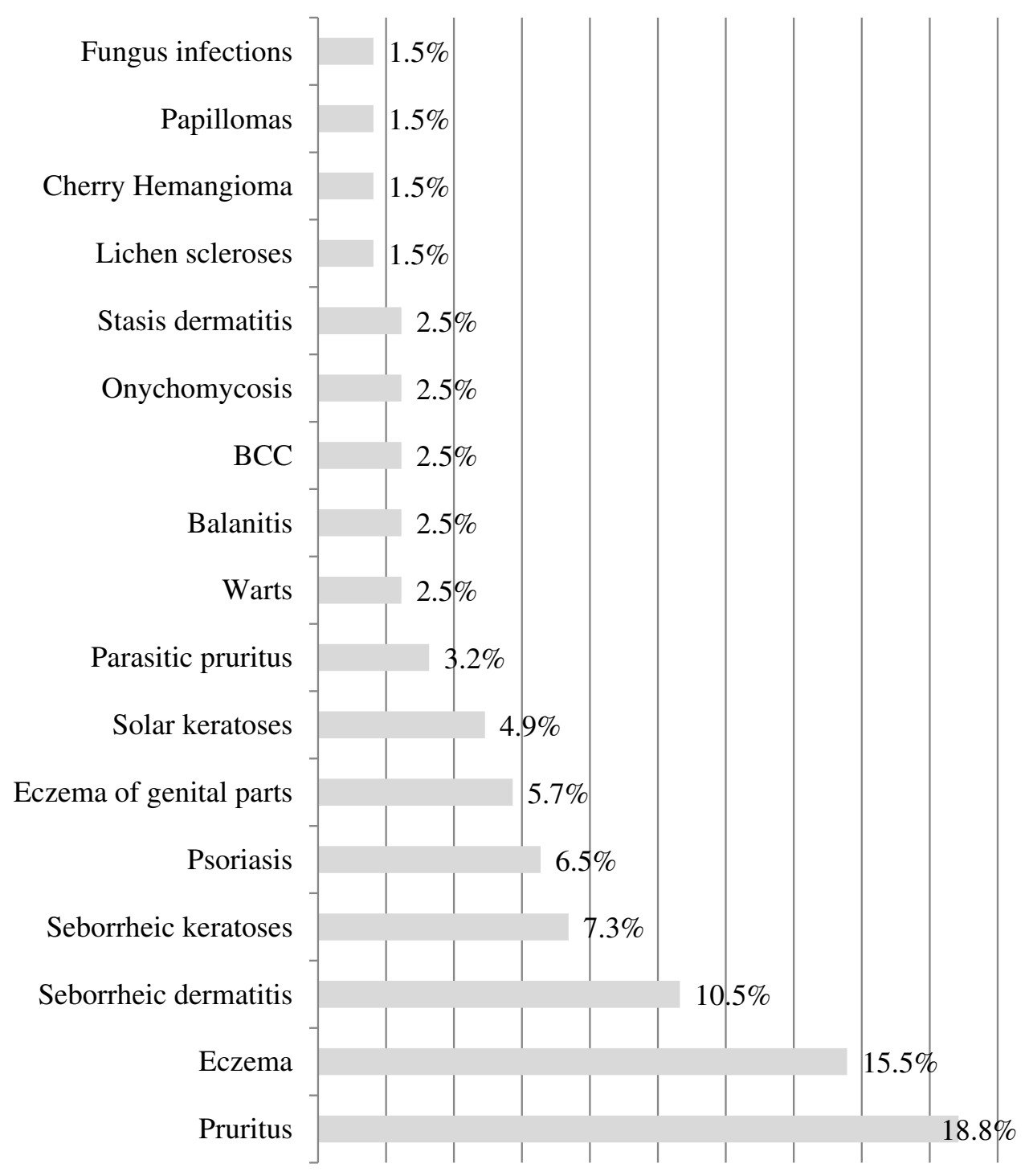

Figure 3 The most common skin diseases in elderly men.

age groups, itching is usually due to urticaria. Its etiology is most often complex and multifactorial. ${ }^{10}$ Elderly skin is thickened in all layers, so tolerance to large changes in environmental temperature is reduced. The winter of 2016-2017 was characterized by extremely low temperatures. As a result, most of older people wore a lot of clothes (feeling cold due to thinning of the skin) which in combination with elevated room temperatures due to house heating, caused a decreased indoor humidity. Decreasing humidity below $50 \%$ gradually leads to a decrease in skin moisture. This situation was worse for those taking antihypertensive drugs with diuretics, thus losing more water. Many elderly people had diabetes mellitus which exacerbated body itching. It is worth noting that a number of older people suffered from anxiety disorders that had aggravating effects on pruritus. There were also some patients suffering from mild to severe renal failure or lymphoma. Both of these conditions are related to pruritus. There have also been cases of patients where after been given laboratory tests to investigate pruritus, they first learnt that they were suffering from diabetes mellitus. ${ }^{11}$ The presence of pruritus is more common in old men than women. This may be due to the higher consumption of alcohol by men, according to their history, which causes an increase in the itching sensation due to alcohol-induced vasodilatation.

Seborrheic dermatitis is also common in the elderly and sometimes appears as a neurological and psychiatric medication side effect with exacerbation of the clinical picture in winter. 


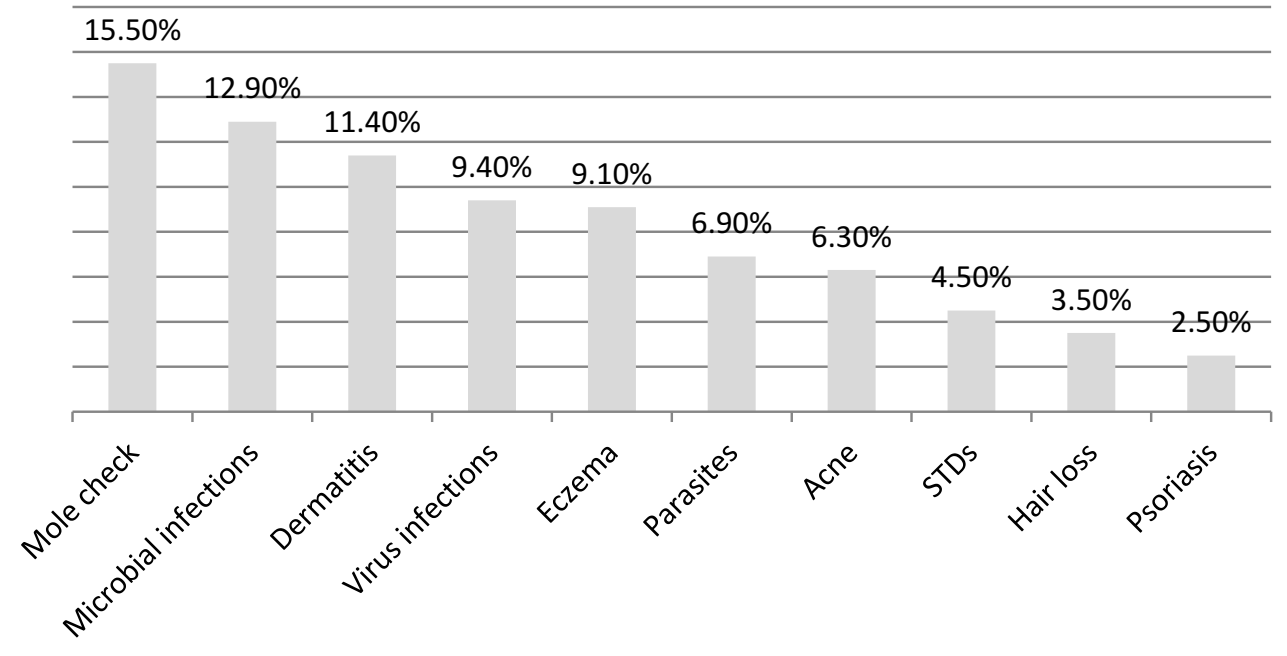

Figure 4 Most common skin diseases in the population under 65 years.

Various forms of eczema and dermatitis were observed in both men and women, which is in accordance with previous studies. ${ }^{12-14}$ One of the most common forms of dermatitis is due to venous insufficiency (varicose veins) of the lower extremities. Other types of eczema that were diagnosed were discoid eczema, eczema of the hands mainly in women due to manual labor (housewife eczema). Occasionally there were cases of eyelid eczema most commonly in women due to the use of cosmetic facial products and hair dyes.

Seborrheic keratoses is usually of no particular clinical interest to dermatologists; however, it is the third most frequent reason for an elderly patient to ask dermatological

Table 2 Most Common Skin Diseases in the Elderly and in People Under 65 Years Old

\begin{tabular}{|l|l|}
\hline Over $\mathbf{6 5}$ Years Old & Under $\mathbf{6 5}$ Years Old \\
\hline Pruritus $14.2 \%$ & Mole Check $15.1 \%$ \\
Eczema $12.4 \%$ & Microbial infections $12.9 \%$ \\
Seborrheic Keratoses 6.8\% & Dermatitis II.4\% \\
Hair loss 6.2\% & Virus infections $9.4 \%$ \\
Onychomycosis 4.9\% & Eczema 9.1\% \\
\hline
\end{tabular}

Table 3 Percentage Correlation of the Most Common Dermatological Diseases of the Elderly with Those of the Rest of the Population

\begin{tabular}{|l|l|l|}
\hline Disease & Over 65 Years Old & Under 65 Years Old \\
\hline Pruritus & $14.2 \%$ & $1 \%$ \\
Eczema & $12.4 \%$ & $9.1 \%$ \\
Seborrheic keratoses & $6.8 \%$ & $0.7 \%$ \\
Hair loss & $6.2 \%$ & $3.5 \%$ \\
Onychomycoses & $4.9 \%$ & $5.3 \%$ \\
\hline
\end{tabular}

advice. They were interested in finding out whether the tumor was benign or malignant and few wanted to remove it.

Hair loss is also a common cause of visits to dermatologist from an early age. Elderly women were more interested in hair loss than men. The elderly found it difficult to accept that aging was associated with increased hair loss. There were cases where other contributing factors to hair loss existed, such as iron deficiency anemia, hypothyroidism and antilipidemic drugs.

Onychomycosis was a common finding as many older people suffer from diabetes mellitus, vascular disorders, and nail plate malformations due to chronic nail injuries from tight shoes. The therapeutic approach had to be primarily with topical creams or nail lacquer in order to eliminate the risk of severe drug interactions (e.g. rhabdomyolysis) of per os antifungal drugs with other medications (e.g. antilipidemic agents).

Psoriasis is more prevalent in men than in women and in both sexes the percentage is higher in the elderly than in the general population. The presence of metabolic syndrome was more pronounced and frequent in elderly psoriatic men than in elderly psoriatic women. No patient was given treatment per os, due to the potential interaction with other medications they were taking for other diseases such as antilipidemic agents. Most were treated mainly with topical treatments and there were some cases where immunomodulatory biological therapy was administered.

The presence of precancerous lesions and skin cancer was significantly higher in elderly patients ${ }^{15,16}$ (Table 4). This difference was due to the fact that most of the men had a large loss of scalp hair, while their work was usually manual with parallel exposure to the sun. ${ }^{17}$ The most common lesion 
Table 4 Percentage Correlation of Precancerous Lesions and Skin Cancer Lesions in the Elderly with Those of the Rest of the Population

\begin{tabular}{|l|l|l|}
\hline Disease & Over 65 Years Old & Under 65 Years Old \\
\hline Solar keratoses & $4 \%$ & $0.7 \%$ \\
Basal cell carcinoma & $2.4 \%$ & $0.5 \%$ \\
\hline
\end{tabular}

locations were the top of the head and the ears and the nose. ${ }^{18}$ Other rare sites were forearms, thighs and spine. ${ }^{19}$ Due to the large number of patients with precancerous and cancerous skin lesions, systematic and regular screening for skin cancer is recommended, especially in the elderly.

Since a significant number of elderly dermatological patients have mobility impairments due to serious health problems, enabling medical home care is necessary. Pruritus and non-cancerous tumors of the elderly are considered to be the main findings of geriatric dermatology.

The contribution of the dermatologist is therefore important in improving quality of life and increasing life expectancy in the elderly.

\section{Disclosure}

The author reports no conflicts of interest in this work.

\section{References}

1. Website:ec.europa.eu.File:Population age structure by major age groups, 2008 and 2018; 2019 (cited April 30,2019). Available from: https://ec.europa.eu/eurostat/statistics-explained/index.php Accessed Feb 4, 2020.

2. Farage MA, Miller KW, Berardesca E, Maibach HI. Clinical implications of aging skin: cutaneous disorders in the elderly. American Journal of Clinical Dermatology. 2009;10(2):73-86. doi:10.2165/ 00128071-200910020-00001

3. Johnson M-LT, Roberts J. Prevalence of Dermatological Diseases Among Persons 1-74 Years of Age. Washington, DC: US Department of Health Education, National Center for Health Statistics; 1978:PHS 79-1660.
4. Jindal R, Jain A, Roy S, Rawat SD, Bhardwaj N. Skin disorders among geriatric population at a tertiary care center in Uttarakhand. J Clin Diagn Res. 2016;10(3):WC06-8. doi:10.7860/JCDR/2016/17015.7500

5. Wilmer EN, Gustafson CJ, Ahn CS, Davis SA, Feldman SR, Huang WW. Most common dermatologic conditions encountered by dermatologists and non-dermatologists. Cutis. 2014;94(6):285-292.

6. Williams HC. Epidemiology of Skin Disease, Rook's Textbook of Dermatology; 2004. Vol. 1. Oxford: Blackwell Publishing; 2014:6.1-6.13.

7. Horn R. The pattern of skin disease in general practice. Dermatol Pract. 1986;2:14-19.

8. Sigurgeisson B, Baran R. The prevalence of onychomycosis in the global population: a literature study. J Eur Acad Dermatol Venereol. 2014;28(11):1480-1491.

9. Misery L, Rahhali N, Duhamel A, Taieb C. Epidemiology of pruritus in France. Acta Derm Venereol. 2012;92:449-581.

10. Valdes-Rodriguez R, Mollanazar NK, González-Muro J, et al. Itch prevalence and characteristics in a Hispanic geriatric population: a comprehensive study using a standardized itch questionnaire. Acta Derm Venereol. 2015;95(4):417-421. doi:10.2340/00015555-1968

11. Reszke R, Pełka D, Walasek A, Machaj Z, Reich A. Skin disorders in elderly subjects. Int J Dermatol. 2015;54(9):e332-8. doi:10.1111/ ijd.2015.54.issue-9

12. Andersen K, Davis MD, Mark DP. The epidemiology of skin and skin-related diseases: a review of population-based studies performed by using the rochester epidemiology project. Mayo Clinic Proc. 2013;88(12):1462-1467. doi:10.1016/j.mayocp.2013.08.018

13. Gaulding JV, Gutierrez D, Bhatia BK, et al. Epidemiology of skin diseases in a diverse patient population. J Drugs Dermatol. 2018;17 (10):1032-1036.

14. Rea JN, Newhouse ML, Halil T. Skin disease in Lambeth. A community study of prevalence and use of medical care. $\mathrm{Br}$ J Prev Soc Med. 1976;30:107-114. doi:10.1136/jech.30.2.107

15. Marks R, Staples M, Giles G. Trends in non-melanocytic skin cancer treated in Australia: the second national survey. Int J Cancer. 1993;53 (4):585-590. doi:10.1002/(ISSN)1097-0215

16. Memon AA, Tomenson JA, Bothwell J, Friedmannn PS. Prevalence of solar damage and actinic keratosis in a Merseyside population. $\mathrm{Br}$ $J$ Dermatol. 2000;142:1154-1159. doi:10.1046/j.1365-2133.2000. 03541.x

17. Templier C, Boulanger E, Boumbar Y, et al. Systematic skin examination in an acute geriatric unit: skin cancer prevalence. Clin Exp Dermatol. 2015;40(4):356-360. doi:10.1111/ced.2015.40.issue-4

18. Cinotti E, Perrot JL, Labeille B, et al. Skin tumours and skin aging in 209 French elderly people: the PROOF study. Eur J Dermatol. 2016;26(5):470-476. doi:10.1684/ejd.2016.2838

19. Rubegni P, Poggiali S, Nami N, Rubegni M, Fimiani M. Skin diseases in geriatric patients: our experience from a public skin outpatient clinic in Siena. G Ital Dermatol Venereol. 2012;147(6):631-636.
Clinical, Cosmetic and Investigational Dermatology is an international, peer-reviewed, open access, online journal that focuses on the latest clinical and experimental research in all aspects of skin disease and cosmetic interventions. This journal is indexed on CAS.
The manuscript management system is completely online and includes a very quick and fair peer-review system, which is all easy to use. Visit http://www.dovepress.com/testimonials.php to read real quotes from published authors. 